\title{
Electron paramagnetic resonance and photoluminescence study of Er-impurity complexes in Si
}

\author{
J. D. Carey, ${ }^{*}$ R. C. Barklie, and J. F. Donegan \\ Department of Physics, Trinity College, Dublin, Ireland \\ F. Priolo \\ INFM and Dipartimento di Fisica, Università di Catania, Corso Italia 57, I 95129 Catania, Italy \\ G. Franzò and S. Coffa \\ CNR-IMETEM, Stradale Primosole 50, I 95121 Catania, Italy \\ (Received 27 April 1998; revised manuscript received 6 August 1998)
}

\begin{abstract}
Electron paramagnetic resonance (EPR) and photoluminescence (PL) spectroscopy have been used to examine the structure and optical properties of erbium-impurity complexes formed in float-zone Si by multipleenergy implants at $77 \mathrm{~K}$ of Er together with either $\mathrm{O}$ or $\mathrm{F}$. After implantation a 2- $\mu \mathrm{m}$-thick amorphous layer was formed containing an almost uniform concentration of $\operatorname{Er}\left(10^{19} / \mathrm{cm}^{3}\right)$ and $\mathrm{O}\left(3 \times 10^{19} / \mathrm{cm}^{3} \mathrm{or}^{20} / \mathrm{cm}^{3}\right)$ or $\mathrm{F}\left(10^{20} / \mathrm{cm}^{3}\right)$. Samples were annealed in nitrogen at $450{ }^{\circ} \mathrm{C}$ for $30 \mathrm{~min}$ (treatment $A$ ), treatment $A+620^{\circ} \mathrm{C}$ for $3 \mathrm{~h}$ (treatment $B$ ), treatment $B+900{ }^{\circ} \mathrm{C}$ for $30 \mathrm{~s}$ (treatment $C$ ) or treatment $B+900{ }^{\circ} \mathrm{C}$ for $30 \mathrm{~min}$ (treatment $D$ ). Samples coimplanted to have $3 \times 10^{19} \mathrm{O} / \mathrm{cm}^{3}$ and subject to treatment $C$ show a broad line anisotropic EPR spectrum. These samples have the most intense low-temperature PL spectrum containing several sharp peaks attributed to $\mathrm{Er}^{3+}$ in sites with predominantly cubic $T_{d}$ symmetry. Increasing the $\mathrm{O}$ concentration to $10^{20} / \mathrm{cm}^{3}$ produces sharp line EPR spectra the strongest of which are attributed to two $\mathrm{Er}^{3+}$ centers having monoclinic $C_{1 h}$ and trigonal symmetry. The principal $g$ values and tilt angle for the monoclinic centers are $g_{1}=0.80$, $g_{2}=5.45, g_{3}=12.60, \tau=57.3^{\circ}, g_{\|}=0.69$, and $g_{\perp}=3.24$ for the trigonal centers. The low-temperature PL spectrum from this sample showed additional sharp lines but the total intensity is reduced when compared to the sample with $3 \times 10^{19} \mathrm{O} / \mathrm{cm}^{3}$. For the sample containing $10^{20} \mathrm{O} / \mathrm{cm}^{3}$ at least four distinct centers are observed by EPR after treatment $B$ but after treatment $D$ no EPR spectrum is observed. The PL spectra are also observed to change depending on the specific anneal treatment but even after treatment $D$, Er-related PL is still observed. Samples containing $10^{20} \mathrm{~F} / \mathrm{cm}^{3}$ and annealed with either treatment $B$ or $C$ produced an EPR spectrum attributed to $\mathrm{Er}^{3+}$ in a site of monoclinic $C_{1 h}$ symmetry with $g_{1}=1.36, g_{2}=9.65, g_{3}=7.91$, and $\tau$ $=79.1^{\circ}$. Tentative models for the structures of Er-impurity complexes are presented and the relationship between the EPR-active and PL-active centers is discussed. [S0163-1829(99)04503-8]
\end{abstract}

\section{INTRODUCTION}

Semiconductors doped with rare-earth ions are the subject of a considerable amount of research due to their applications in optoelectronics. ${ }^{1-16}$ The $4 f$ electrons are shielded from the full effects of the host crystal field and this results in the intra- $4 f$ shell optical transitions being both sharp and nearly independent of the host material. Furthermore, due to the close proximity of the $4 f$ electrons to the nucleus, these electrons experience a strong spin-orbit interaction. Erbium doped silicon has attracted particular attention because the ${ }^{4} I_{13 / 2}$ to ${ }^{4} I_{15 / 2}$ transition in $\mathrm{Er}^{3+}$ occurs at the technologically important wavelength of $1.54 \mu \mathrm{m}$. This wavelength matches the minimum in the absorption of light in silica-based optical fibers and is thus important in optical fiber communication. When Er ions are incorporated into $\mathrm{Si}$, this transition can be excited both optically ${ }^{4}$ and electrically. ${ }^{5}$ Indeed, Er doping of $\mathrm{Si}$ is one of the most successful ways in obtaining light emission from this semiconductor, ${ }^{1,2}$ thus circumventing the intrinsic inability of Si to provide efficient light emission. One of the principal problems in the development of Er-doped $\mathrm{Si}$ has been the strong quenching behavior of both the photoluminescence (PL) and electroluminescence (EL) on going from $77 \mathrm{~K}$ to room temperature. ${ }^{3,4}$ It had been observed that over this temperature range the PL intensity decreased by over three orders of magnitude. However, in the presence of suitable concentrations of impurities such as $\mathrm{O}$ or $\mathrm{F}$ it has been shown that the PL intensity decreased only by a factor of $30 .^{6}$ This has led to the observation of room-temperature EL from Er-doped Si $p$ - $n$ diodes codoped with $\mathrm{O}$ or $\mathrm{F}^{5,7}$ In addition to reducing the quenching of the PL, the presence of the impurities can increase the net solubility of $\mathrm{Er}$ in $\mathrm{Si}$. The solid solubility ${ }^{8}$ of $\mathrm{Er}$ in $\mathrm{Si}$ is low $\left(\sim 2 \times 10^{16} / \mathrm{cm}^{3}\right)$ and to increase it nonequilibrium techniques such as molecularbeam epitaxy, ${ }^{9,10}$ chemical vapor deposition, ${ }^{11}$ or ion implantation $^{6,12}$ must be employed. At concentrations above the solubility limit, precipitation of Er into Er silicide will occur. Coimplantation with either $\mathrm{O}$ or $\mathrm{F}$ has been shown to help in suppressing precipitation and Er concentrations as high as of $1 \times 10^{19} / \mathrm{cm}^{3}$ have been incorporated in a goodquality Si single crystal by ion implantation. ${ }^{6,13}$ These beneficial effects have been attributed to modifications in the local environment of the Er atom through the formation of Er-impurity complexes. ${ }^{14-16}$ It is therefore of great interest to determine the structure of these complexes. Some information has already been obtained from extended x-rayabsorption fine-structure (EXAFS) measurements, which showed that Er is surrounded by a cage of 4-6 O atoms. ${ }^{15,16}$ 
Electron paramagnetic resonance (EPR) is one of the most powerful experimental techniques used to examine defects and complexes in semiconductors. ${ }^{17}$ Furthermore, EPR is able to distinguish between the two common Er valence states, $\mathrm{Er}^{2+}$ and $\mathrm{Er}^{3+} . \mathrm{Er}^{2+}$ has $124 f$ electrons and is thus a non-Kramers ion whereas $\mathrm{Er}^{3+}$, having an odd number of electrons, is a Kramers ion. ${ }^{17}$ To date there has only been one report ${ }^{18}$ of a weak EPR signal from Er-doped Czochralski (CZ) grown Si but this was only observed with aboveband-gap illumination. It was concluded that this EPR signal was due to an ionized state of a defect with a $2+$ charge ground state; no Er-related photoluminescence was observed from this defect. Recently, we have reported a preliminary EPR study on Er-doped Si and indeed we have shown the presence of $\mathrm{Er}^{3+}$ centers in $\mathrm{Si}^{19}$ In this paper we present the first detailed EPR study of Er complexes in Si implanted with Er together with either O or F. We show that the nature of the coimplanted ions as well as their concentrations and the postimplantation anneal treatments all affect the structure and/or the concentration of the Er complexes. The relationship between the EPR-active centers and the optically active centers is examined using high-resolution PL measurements.

\section{EXPERIMENT}

Samples of $n$-type FZ (100) wafers (resistivity $\sim 220$ $\Omega \mathrm{cm}$ ) were implanted with Er ions at $77 \mathrm{~K}$ using a 1.7-MV tandem accelerator and a sputter ion source with an Er oxide cathode. All the samples investigated were implanted with Er to a total fluence of $1 \times 10^{15} / \mathrm{cm}^{2}$ with energies in the range $0.5-5 \mathrm{MeV}$ to give an approximately uniform concentration of $1 \times 10^{19} \mathrm{Er} / \mathrm{cm}^{3}$ over most of the implanted region. One sample (Er1) was only implanted with Er. The other samples were coimplanted with $\mathrm{O}$ or $\mathrm{F}$ at different energies in the range $0.15-0.5 \mathrm{MeV}$ to give approximately uniform impurity concentrations in the region where Er resides. One sample (O1) has an $\mathrm{O}$ concentration of approximately $3 \times 10^{19} / \mathrm{cm}^{3}$ in the region between 0.3 and $1.8 \mu \mathrm{m}$ below the surface resulting in a nearly constant 3:1 O:Er concentration ratio in most of the implanted region as measured by secondary ion mass spectrometry (SIMS). A third sample $(\mathrm{O} 2)$ was implanted with $\mathrm{O}$ in order to have an almost constant $\mathrm{O}$ concentration of $1 \times 10^{20} / \mathrm{cm}^{3}$ and a 10:1 O:Er concentration ratio in most of the implanted region. After implantation a continuous amorphous layer extends from the surface to a depth of over $2.0 \mu \mathrm{m}$ as measured by transmission electron microscopy (TEM). Each sample was annealed at $450^{\circ} \mathrm{C}$ for 30 min to smooth the amorphous-crystalline interface and most were then subsequently annealed for $3 \mathrm{~h}$ at $620^{\circ} \mathrm{C}$ in order to induce the solid phase epitaxial (SPE) recrystallization of the amorphous layer. Finally thermal annealing under flowing $\mathrm{N}_{2}$ for $30 \mathrm{~s}$ or $30 \mathrm{~min}$ at $900{ }^{\circ} \mathrm{C}$ was performed on some of the samples.

To examine the effects of different post-implantation treatments, three samples, in addition to $\mathrm{O} 2$, each with 1 $\times 10^{19} \mathrm{Er} / \mathrm{cm}^{3}$ and $1 \times 10^{20} \mathrm{O} / \mathrm{cm}^{3}$ were annealed under different conditions. Sample $\mathrm{O} 3$ was just annealed at $450^{\circ} \mathrm{C}$ for 30 min (treatment $A$ ), and sample $\mathrm{O} 4$ was annealed at $450{ }^{\circ} \mathrm{C}$ for $30 \mathrm{~min}$ followed by $620^{\circ} \mathrm{C}$ for $3 \mathrm{~h}$ (treatment $B$ ). Sample O5 received treatment $B$ but was then subject to a hightemperature annealing at $900{ }^{\circ} \mathrm{C}$ for $30 \mathrm{~min}$ (treatment $D$ ).
TABLE I. Sample labels, implanted impurity concentrations and annealing treatments for the samples investigated. Treatment $A$ : Annealed at $450{ }^{\circ} \mathrm{C}$ for $30 \mathrm{~min}$. Treatment $B$ : Annealed at $450{ }^{\circ} \mathrm{C}$ for $30 \mathrm{~min}+620^{\circ} \mathrm{C}$ for $3 \mathrm{~h}$. Treatment $C$ : Annealed at $450{ }^{\circ} \mathrm{C}$ for 30 $\min +620^{\circ} \mathrm{C}$ for $3 \mathrm{~h}+900{ }^{\circ} \mathrm{C}$ for $30 \mathrm{~s}$. Treatment $D$ : Annealed at $450{ }^{\circ} \mathrm{C}$ for $30 \mathrm{~min}+620^{\circ} \mathrm{C}$ for $3 \mathrm{~h}+900{ }^{\circ} \mathrm{C}$ for $30 \mathrm{~min}$.

\begin{tabular}{clc}
\hline \hline $\begin{array}{c}\text { Sample } \\
\text { label }\end{array}$ & \multicolumn{1}{c}{ Impurity concentrations } & $\begin{array}{c}\text { Annealing } \\
\text { treatment }\end{array}$ \\
\hline Er1 & $1 \times 10^{19} \mathrm{Er} / \mathrm{cm}^{3}$ & $C$ \\
$\mathrm{O} 1$ & $1 \times 10^{19} \mathrm{Er} / \mathrm{cm}^{3}+3 \times 10^{19} \mathrm{O} / \mathrm{cm}^{3}$ & $C$ \\
$\mathrm{O} 2$ & $1 \times 10^{19} \mathrm{Er} / \mathrm{cm}^{3}+1 \times 10^{20} \mathrm{O} / \mathrm{cm}^{3}$ & $C$ \\
$\mathrm{O} 3$ & $1 \times 10^{19} \mathrm{Er} / \mathrm{cm}^{3}+1 \times 10^{20} \mathrm{O} / \mathrm{cm}^{3}$ & $A$ \\
$\mathrm{O} 4$ & $1 \times 10^{19} \mathrm{Er} / \mathrm{cm}^{3}+1 \times 10^{20} \mathrm{O} / \mathrm{cm}^{3}$ & $B$ \\
$\mathrm{O} 5$ & $1 \times 10^{19} \mathrm{Er} / \mathrm{cm}^{3}+1 \times 10^{20} \mathrm{O} / \mathrm{cm}^{3}$ & $D$ \\
$\mathrm{~F} 1$ & $1 \times 10^{19} \mathrm{Er} / \mathrm{cm}^{3}+1 \times 10^{20} \mathrm{~F} / \mathrm{cm}^{3}$ & $B$ \\
$\mathrm{~F} 1$ & $1 \times 10^{19} \mathrm{Er} / \mathrm{cm}^{3}+1 \times 10^{20} \mathrm{~F} / \mathrm{cm}^{3}$ & $C$ \\
\hline \hline
\end{tabular}

Finally to examine the effects of different coimplanted impurity atoms, two samples were coimplanted with $\mathrm{F}$ at $77 \mathrm{~K}$. The same ion energies and doses were used for F coimplantation as were used in the coimplantation of sample $\mathrm{O} 2$ and this resulted in an nearly constant 10:1 F:Er concentration ratio in most of the implanted region. To examine the effects of different annealing conditions, one sample, labeled F1, was subjected to thermal treatment $B\left(450^{\circ} \mathrm{C}\right.$ for $30 \mathrm{~min}$ $+620^{\circ} \mathrm{C}$ for $3 \mathrm{~h}$ ). The second sample, F2, was subjected to treatment $C\left(450{ }^{\circ} \mathrm{C}\right.$ for $30 \mathrm{~min}+620^{\circ} \mathrm{C}$ for $3 \mathrm{~h}+900^{\circ} \mathrm{C}$ for $30 \mathrm{~s})$. Table I summarizes the impurity content and annealing conditions of the samples examined.

EPR measurements were performed in a modified Bruker EPR spectrometer with $100 \mathrm{kHz}$ field modulation using a $\mathrm{TE}_{102}$ rectangular cavity. The microwave frequency was approximately $9.23 \mathrm{GHz}$ and the samples were cooled to helium temperatures using an Oxford Instruments flow cryostat. The sample temperature was approximately $10 \mathrm{~K}$ and care was taken not to saturate the EPR spectra with microwave power. Each of the samples were cleaved such that a [100] direction was parallel to the vertical sample rotation axis. This allowed the orientational dependence of the EPR spectrum in the $(1 \overline{10})$ plane to be measured. PL measurements were performed using the 488-nm line of an $\mathrm{Ar}^{+}$laser with a pump power of $200 \mathrm{~mW}$. The pump beam was focused to a 1-mm-diam spot on the sample and mechanically chopped at a frequency of $55 \mathrm{~Hz}$. The PL signal was collected by two lenses, analyzed with a monochromator and detected with a North Coast liquid-nitrogen-cooled Ge detector. Spectra were recorded using a lock-in amplifier with the chopper frequency as a reference. Low-temperature measurements were performed by using a closed-cycle liquid-He cooler system with the samples kept in vacuum.

\section{EXPERIMENTAL RESULTS}

\section{A. Effects of oxygen codoping on the EPR spectra of Er-doped Si}

The low-temperature EPR spectrum from sample Er1 (not shown) revealed only a broad isotropic resonance corresponding to a $g$ value of 10.5. The peak-to-peak linewidth of this line was $23 \mathrm{mT}$ and the line shape of this broad reso- 


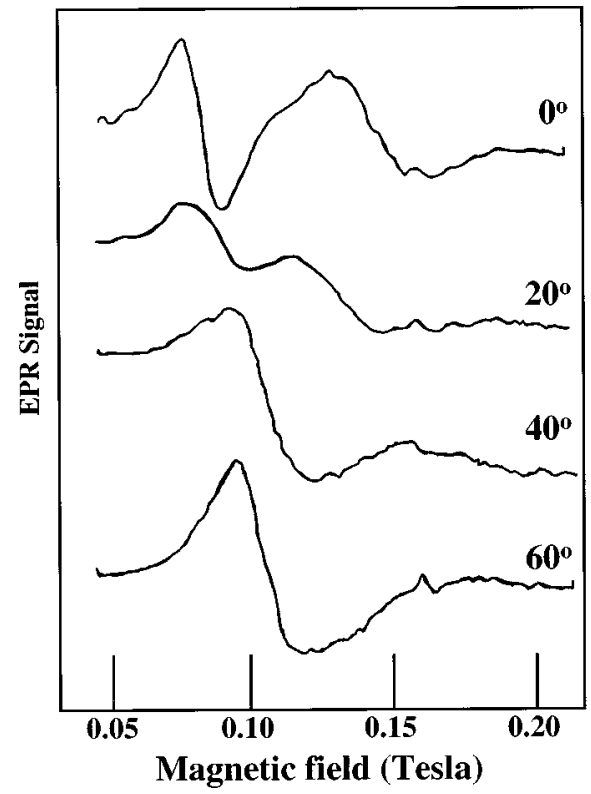

FIG. 1. Low-temperature EPR spectra from sample O1 $\left(10^{19} \mathrm{Er} / \mathrm{cm}^{3}+3 \times 10^{19} \mathrm{O} / \mathrm{cm}^{3}+450{ }^{\circ} \mathrm{C}\right.$ for $30 \mathrm{~min}+620{ }^{\circ} \mathrm{C}$ for 3 $\mathrm{h}+900{ }^{\circ} \mathrm{C}$ for $\left.30 \mathrm{~s}\right)$ at different orientations of the magnetic field in the $(1 \overline{1} 0)$ plane. The angle indicated is that between the magneticfield direction and [001].

nance did not change in a significant way as the magnetic field was rotated in the (110) plane of the sample. The EPR spectrum of sample O1, shown in Fig. 1, reveals the presence of two broad resonances which merge together as the magnetic field was rotated in the $(1 \overline{1} 0)$ plane through $60^{\circ}$ from the [001] direction. No significant change in the spectrum occurred between $60^{\circ}$ and $90^{\circ}$. In contrast to samples Er1 and $\mathrm{O} 1$, sample $\mathrm{O} 2$ has an EPR spectrum containing several sharp lines, as shown in Fig. 2, when the magnetic field is nearly parallel to [001]. Three distinct groupings of lines are evident: a series of sharp low-field lines in the range $0-0.15$ $\mathrm{T}$ (lines 1-3), a broader line at approximately $0.25 \mathrm{~T}$ (line 4) and a single sharp isotropic line (not shown) with a $g$ value of 2.00457 ; the later is observed in all of the samples examined and we believe that this line originates from the underlying Si substrate. Lines 1-3 arise from centers (here labeled OEr-1) whose orientational dependence could be fitted, as shown in Fig. 3, to the effective spin Hamiltonian

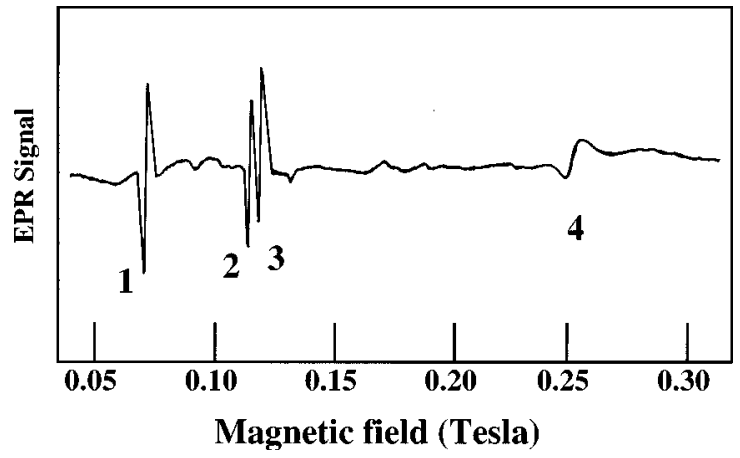

FIG. 2. Low-temperature EPR spectra from sample $\mathrm{O} 2$ $\left(10^{19} \mathrm{Er} / \mathrm{cm}^{3}+10 \times 10^{20} \mathrm{O} / \mathrm{cm}^{3}+450{ }^{\circ} \mathrm{C}\right.$ for $30 \mathrm{~min}+620^{\circ} \mathrm{C}$ for 3 $\mathrm{h}+900{ }^{\circ} \mathrm{C}$ for $30 \mathrm{~s}$ ) for the magnetic field nearly parallel to the [001] direction. The microwave frequency was $9.23 \mathrm{GHz}$.

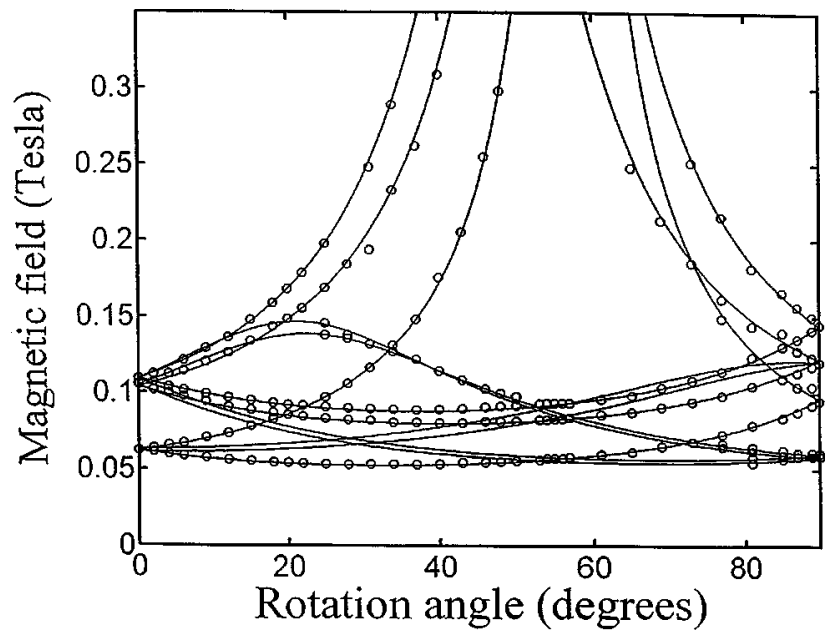

FIG. 3. Angular dependence of the observed resonances (open circles) from center OEr-1 in sample O2 $\left(10^{19} \mathrm{Er} / \mathrm{cm}^{3}\right.$ $+10^{20} \mathrm{O} / \mathrm{cm}^{3}+450{ }^{\circ} \mathrm{C}$ for $30 \mathrm{~min}+620^{\circ} \mathrm{C}$ for $3 \mathrm{~h}+900{ }^{\circ} \mathrm{C}$ for 30 $\mathrm{s})$ as the magnetic field is rotated in a plane near the (110) plane. Due to the slight misorientation of the sample, the magnetic field is not exactly in the $(1 \overline{1} 0)$ plane of the sample and this produces more lines than would be expected for $C_{1 h}$ symmetry. The fit (solid lines) is obtained from the principal $g$ values and tilt angle given in the text.

$$
H=\mu_{B} B \cdot g \cdot S
$$

with $S=\frac{1}{2}$ and a $g$ tensor exhibiting $C_{1 h}$ monoclinic symmetry. The principal $g$ values are $g_{1}=0.80, g_{2}=5.45$, and $g_{3}$ $=12.60$. The 2 -axis lies in a $\langle 110\rangle$ direction and both the 1and 3-axes lie in the plane perpendicular to it with the 1-axis tilted away by an angle $\tau$ from the [001] direction as shown in Fig. 4. For center OEr-1 the angle $\tau$ is $57.3^{\circ}$. These parameters were obtained by fitting the angular dependence of the spectrum as the magnetic field was rotated approximately with the (110) plane. The analysis shows that the rotation axis was not quite coincident with the $\langle 110\rangle$ direction with the result that the closest approach of the field direction to the [001] and [110] directions was $1.4^{\circ}$ and $3.2^{\circ}$, respectively. The rotation angle is the angle through which the field is rotated and is defined to be zero at the closest approach to the [001] direction. It is this slight misalignment that leads to the splitting of lines 2 and 3 in Fig. 2 and the expected

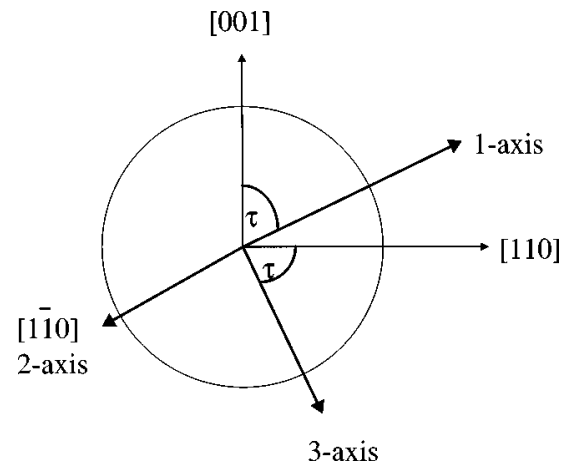

FIG. 4. The principal axes system for monoclinic $C_{1 h}$ symmetry. The 1-axis is tilted away from a $\langle 001\rangle$ direction by an angle $\tau$. Both the 1- and 3-axes lie in the (110) plane and the 2-axis lies perpendicular to this plane. 


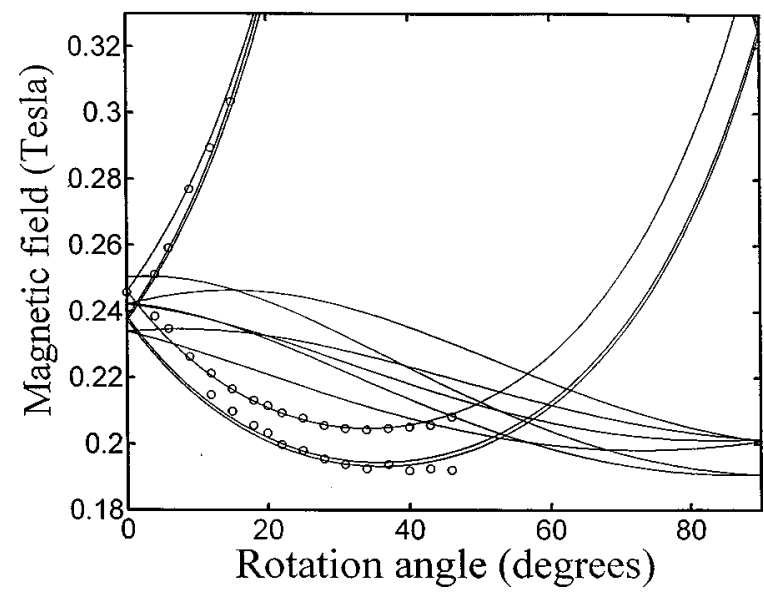

FIG. 5. Angular dependence of the observed low-field resonances (open circles) and fit for center OEr-2 in sample $\mathrm{O} 2$ $\left(10^{19} \mathrm{Er} / \mathrm{cm}^{3}+10^{20} \mathrm{O} / \mathrm{cm}^{3}+450{ }^{\circ} \mathrm{C}\right.$ for $30 \mathrm{~min}+620^{\circ} \mathrm{C}$ for 3 $\mathrm{h}+900{ }^{\circ} \mathrm{C}$ for $30 \mathrm{~s}$ ). The same misorientation parameters as used in center OEr-1 are used in the analysis of center OEr-2.

presence of 12 lines in the angular dependence of the spectrum shown in Fig. 3 rather than the seven that would be expected for $C_{1 h}$ symmetry if the magnetic field was exactly in the $(1 \overline{1} 0)$ plane. ${ }^{19}$

Line 4 in Fig. 2 has a peak-to-peak linewidth of $7.7 \mathrm{mT}$ but splits into several lines as the field direction is rotated away from [001]. Figure 5 shows the angular dependence of these lines as the magnetic field is rotated in approximately the $(1 \overline{10})$ plane (the misorientation is the same as that described above). As the rotation angle was increased, the intensities of these lines diminished sharply and it was not possible to follow the lines beyond a rotation angle of about $45^{\circ}$. Using the available data it was possible to fit them by using the same monoclinic Hamiltonian as in Eq. (1). The principal $g$ values obtained from the fitting are $g_{1}=0.45, g_{2}$ $=3.46$, and $g_{3}=3.22$. The tilt angle $\tau$ is $55.9^{\circ}$ and this center is labeled OEr-2. Since $g_{2} \approx g_{3}$ and $\tau$ is close to $54.74^{\circ}$ the center exhibits near trigonal symmetry. The fact that the line positions were only obtained for a limited angular range limits the reliability of the fit and the subsequent $g$ values obtained for it. However, as presented in Sec. III B, we observe a more intense signal in another sample (O4), for which no misorientation occurred, which we believe is due to the same center and for which the full angular dependence was obtained to allow a more accurate determination of the $g$ values. For none of the spectra, which for reasons given in the

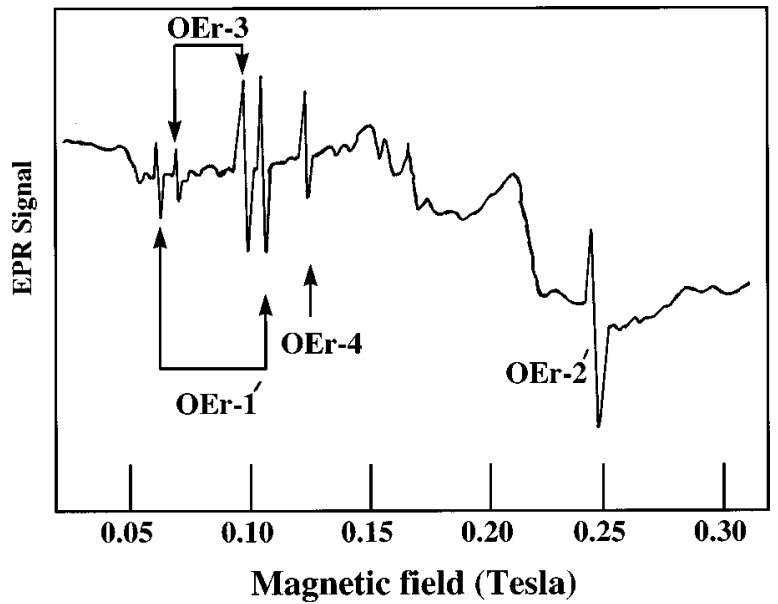

FIG. 6. Low-temperature EPR spectra from sample $\mathrm{O} 4$ $\left(10^{19} \mathrm{Er} / \mathrm{cm}^{3}+10^{20} \mathrm{O} / \mathrm{cm}^{3}+450{ }^{\circ} \mathrm{C}\right.$ for $30 \mathrm{~min}+620{ }^{\circ} \mathrm{C}$ for $\left.3 \mathrm{~h}\right)$ for the magnetic field parallel to the [001] direction. The microwave frequency was $9.23 \mathrm{GHz}$. For convenience the lines associated with the centers $\mathrm{OEr}-1^{\prime}$, OEr-3, OEr-4, and $\mathrm{OEr}-2^{\prime}$ for this orientation are indicated on the spectrum.

discussion we suggest are associated with $\mathrm{Er}^{3+}$ centers, were we able to detect the hyperfine lines associated with the $23 \%$ abundant $\operatorname{Er}^{167}$ isotope with $I=\frac{7}{2} .{ }^{20}$

\section{B. Effects of different annealing treatments on the EPR spectra of the $O$ codoped samples}

The samples labeled $\mathrm{O} 2, \mathrm{O} 3, \mathrm{O} 4$, and $\mathrm{O} 5$ have the same impurity concentrations $\left(10^{19} \mathrm{Er} / \mathrm{cm}^{3}+10^{20} \mathrm{O} / \mathrm{cm}^{3}\right)$ but have been subjected to different thermal annealing treatments. The results for sample $\mathrm{O} 2$ are given in the previous section. From sample O3 and sample O5 no Er-related EPR was observed, whereas from sample $\mathrm{O} 4$ many lines were observed most of which are associated with $\mathrm{Er}^{3+}$ complexes. Figure 6 shows the EPR spectrum from sample O4 obtained for the magnetic field parallel to the [001] direction. No misorientation of the sample in the magnetic field occurred in this case. Upon

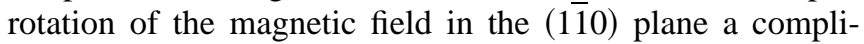
cated orientational dependence was observed. The angular dependence of many of these lines could only be accounted for by assuming the presence of four different centers. Two of these centers OEr-1' and OEr-3 exhibit monoclinic symmetry and the other two, OEr- $2^{\prime}$ and OEr-4 exhibit trigonal symmetry. Table II lists the principal $g$ value and tilt angles obtained from the fits to the angular dependence for each

TABLE II. Principal $g$ values for the different centers observed in samples O2, O4, and F1.

\begin{tabular}{ccccccc}
\hline \hline Sample & Center & $g_{1}$ & $g_{2}$ & $g_{3}$ & $\begin{array}{c}\text { Average } \\
g \text { value }^{\mathrm{a}}\end{array}$ & Tilt angle $^{\circ}$ \\
\hline O2 & OEr-1 & 0.80 & 5.45 & 12.60 & 6.28 & $57.30^{\circ}$ \\
O4 & OEr-1' & 0.80 & 5.45 & 12.55 & 6.27 & $56.90^{\circ}$ \\
O4 & OEr-3 & 1.09 & 5.05 & 12.78 & 6.31 & $48.30^{\circ}$ \\
O4 & OEr-4 & 2.00 & 6.23 & 6.23 & 4.82 & $54.74^{\circ}$ \\
O2 & OEr-2 & 0.45 & 3.46 & 3.22 & 2.38 & $55.90^{\circ}$ \\
O4 & OEr-2' & 0.69 & 3.24 & 3.24 & 2.39 & $54.74^{\circ}$ \\
F1 & FEr-1 & 1.36 & 9.65 & 7.91 & 6.31 & $79.10^{\circ}$ \\
\hline \hline
\end{tabular}




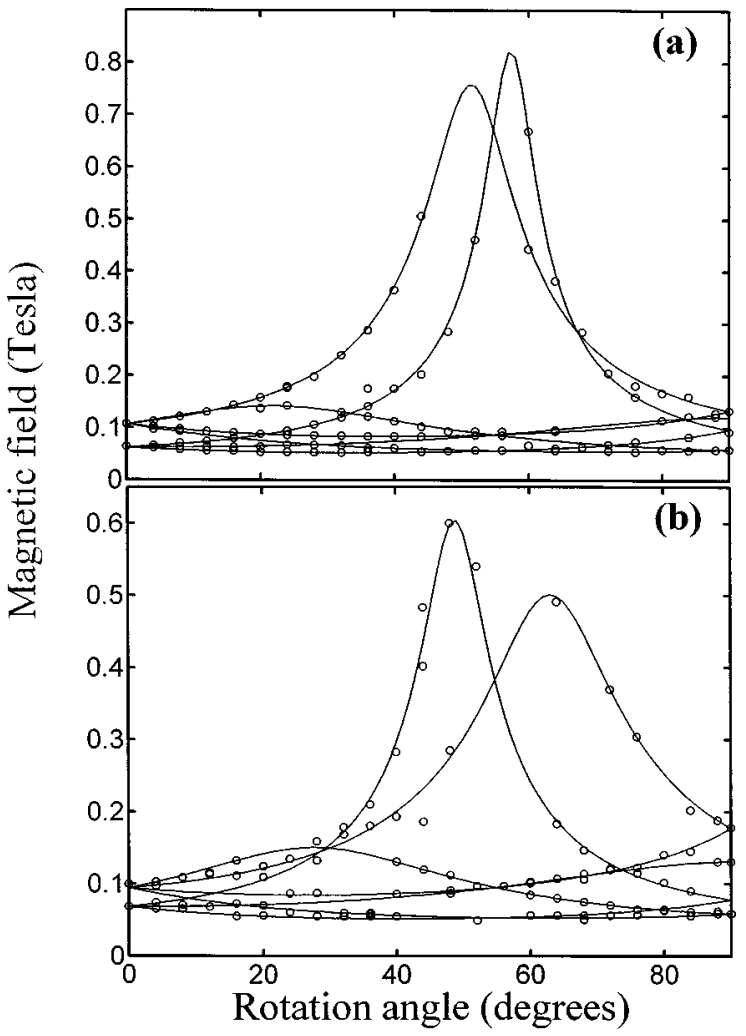

FIG. 7. Angular dependence of the observed low-field resonances (open circles) and fit (continuous line) for monoclinic centers: (a) center OEr-1' and (b) center OEr-3 observed from sample O4 $\left(10^{19} \mathrm{Er} / \mathrm{cm}^{3}+10^{20} \mathrm{O} / \mathrm{cm}^{3}+450{ }^{\circ} \mathrm{C}\right.$ for $30 \mathrm{~min}+620{ }^{\circ} \mathrm{C}$ for $\left.3 \mathrm{~h}\right)$. The same temperature is approximately $10 \mathrm{~K}$ and the microwave frequency is $9.23 \mathrm{GHz}$.

center. Figure 7(a) and 7(b) show the fits obtained to the angular dependence for the monoclinic centers and Fig. 8(a) and $8(\mathrm{~b})$ the fits to the data for the trigonal centers. The $g$ values and tilt angle obtained from the fit to the data in Fig. 7 (a) are the same, within the fitting error, as those obtained for center OEr-1. Consequently we believe that this center, labeled OEr-1' is the same as center OEr-1 found in sample $\mathrm{O} 2$. Furthermore since the $g$ values and tilt angle obtained from the fit to the data shown in Fig. 8(b) are similar to those obtained for center OEr-2, we believe that this center, here labeled OEr-2', is the same as center OEr-2. Since the full angular dependence within the (110) plane was obtained for OEr-2' it is likely that its parameters, given in Table II, are more reliable than for OEr-2.

A number of other unlabelled weaker lines, particularly around 160-170 mT, are seen in Fig. 6. It was not possible to perform a detailed angular dependence measurement on these lines as their intensity diminished upon rotation and these lines are subsequently masked by more intense lines the positions of which are changing as the orientation of the sample changes in the magnetic field; consequently we have not attempted to determine the principle $g$ values of the centers associated with them.

\section{Photoluminescence spectra of O-doped samples}

Figure 9 shows the high-resolution $(\sim 10 \AA)$ photoluminescence spectra from samples $\mathrm{O} 1, \mathrm{O} 2$, and $\mathrm{O} 4$ taken at 15

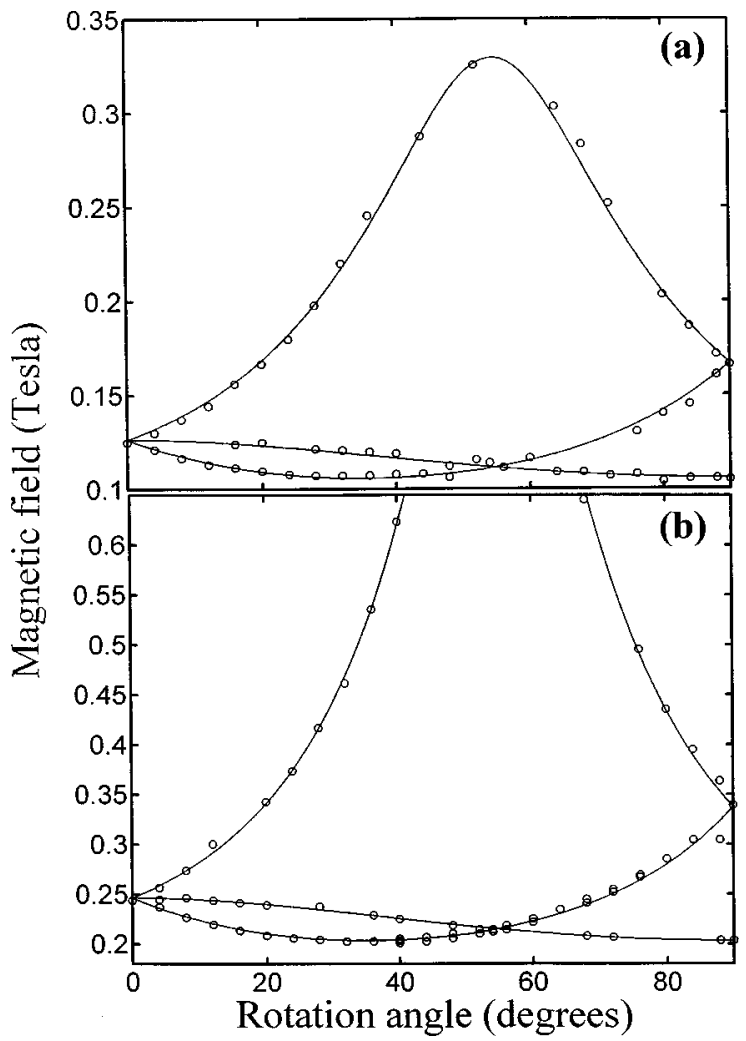

FIG. 8. Angular dependence of the observed low-field resonances (open circles) and fit (continuous line) for trigonal centers: (a) center OEr-4 and (b) center OEr-2' observed from sample O4 $\left(10^{19} \mathrm{Er} / \mathrm{cm}^{3}+10^{20} \mathrm{O} / \mathrm{cm}^{3}+450{ }^{\circ} \mathrm{C}\right.$ for $30 \mathrm{~min}+620{ }^{\circ} \mathrm{C}$ for $\left.3 \mathrm{~h}\right)$. The same temperature is approximately $10 \mathrm{~K}$ and the microwave frequency is $9.23 \mathrm{GHz}$.

$\mathrm{K}$. The PL spectrum from sample O1 reveals the presence of four dominant lines at wavelengths of 1.5376, 1.5559, 1.5748 , and $1.5991 \mu \mathrm{m}$. The strongest of these lines is at $1.5376 \mu \mathrm{m}$ and has a half-width at half-height of $9.2 \mathrm{~cm}^{-1}$. The PL spectrum of sample $\mathrm{O} 2$ also contains these lines as well as extra lines. The half-width at half-height of the peak at $1.5376 \mu \mathrm{m}$ from sample $\mathrm{O} 2$ is $11.9 \mathrm{~cm}^{-1}$. The temperature dependence of the PL intensity from the two samples has also been studied. ${ }^{13}$ Whilst the intensity of the $1.537-\mu \mathrm{m}$ peak in sample $\mathrm{O} 1$ at $15 \mathrm{~K}$ is approximately a factor of 3 stronger compared to that of sample O2, at RT the corresponding signal is the same in the two samples. As can be seen from Fig. 9 the PL intensity of sample O2 is larger than that found from sample O4. Although both samples have the same impurity concentrations, sample $\mathrm{O} 2$ received an additional high-temperature anneal of $900^{\circ} \mathrm{C}$ for $30 \mathrm{~s}$ (treatment C).

\section{EPR and PL measurements of F coimplanted samples}

Figure 10(a) shows the low temperature $(\sim 10 \mathrm{~K})$ EPR spectrum of sample $\mathrm{F} 1\left(10^{19} \mathrm{Er} / \mathrm{cm}^{3}+10^{20} \mathrm{~F} / \mathrm{cm}^{3}\right.$, thermal treatment $B$ ) with the magnetic field parallel to the [110] direction. Three lines are observed and peak-to-peak linewidths of the most intense lines are $1.2 \mathrm{mT}$ (line 2) and 1.45 $\mathrm{mT}$ (line 3); the spectrum was unobservable above $17 \mathrm{~K}$. The orientational dependence of the spectrum could be fitted, Fig. 10(b), to a single spin- $\frac{1}{2}$ monoclinic $C_{1 h}$ center, labeled 


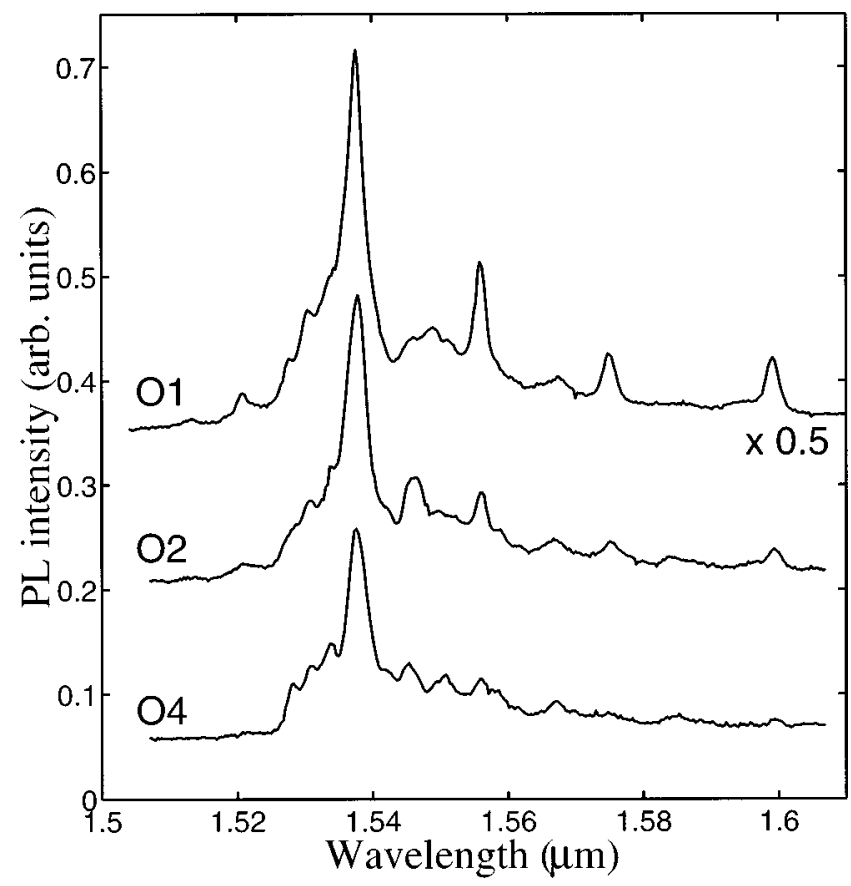

FIG. 9. Low-temperature photoluminescence spectra from sample $\mathrm{O} 1 \quad\left(10^{19} \mathrm{Er} / \mathrm{cm}^{3}+3 \times 10^{19} \mathrm{O} / \mathrm{cm}^{3}+450{ }^{\circ} \mathrm{C}\right.$ for $30 \mathrm{~min}$ $+620^{\circ} \mathrm{C}$ for $3 \mathrm{~h}+900{ }^{\circ} \mathrm{C}$ for $\left.30 \mathrm{~s}\right)$, sample $\mathrm{O} 2\left(10^{19} \mathrm{Er} / \mathrm{cm}^{3}\right.$ $+10^{20} \mathrm{O} / \mathrm{cm}^{3}+450{ }^{\circ} \mathrm{C}$ for $30 \mathrm{~min}+620^{\circ} \mathrm{C}$ for $3 \mathrm{~h}+900{ }^{\circ} \mathrm{C}$ for 30 s), sample $\mathrm{O} 4\left(10^{19} \mathrm{Er} / \mathrm{cm}^{3}+10^{20} \mathrm{O} / \mathrm{cm}^{3}+450{ }^{\circ} \mathrm{C}\right.$ for $30 \mathrm{~min}$ $+620^{\circ} \mathrm{C}$ for $3 \mathrm{~h}$ ). The pump power was $200 \mathrm{~mW}$.

FEr-1, with principle $g$ values $g_{1}=1.36, g_{2}=9.65$, and $g_{3}$ $=7.91$ and a tilt angle of $79.1^{\circ}$. The fourth EPR line expected for $C_{1 h}$ symmetry for the magnetic field parallel to the [110] direction is beyond the magnetic-field range investigated. To investigate the thermal stability of the center FEr-1 sample F1 was annealed under flowing Ar for $15 \mathrm{~min}$ the intervals successively at 800,840 , and $870{ }^{\circ} \mathrm{C}$. After each anneal the sample was cooled to $10 \mathrm{~K}$ and the spectrum recorded for the magnetic field parallel to the [110] direction. After annealing at 800 and $840{ }^{\circ} \mathrm{C}$ the intensities of lines 2 and 3 had both fallen to $65 \%$ and $40 \%$, respectively, of their initial values. No EPR signal from center FEr-1 was detected after annealing at $870^{\circ} \mathrm{C}$. We also recorded the EPR spectra of another sample F2, which was codoped in the same way as $\mathrm{F} 1$ but which had received a $30 \mathrm{~s}$ anneal at $900^{\circ} \mathrm{C}$ in addition to the anneals at $450{ }^{\circ} \mathrm{C}$ and $620^{\circ} \mathrm{C}$ (treatment $\mathrm{C}$ ). This sample gave the same spectrum as $\mathrm{F} 1$ but reduced in intensity by about a factor of 2 . That the spectrum was seen at all despite the final anneal temperature exceeding $870^{\circ} \mathrm{C}$ is undoubtedly due to the fact that the anneal at $900{ }^{\circ} \mathrm{C}$ was only for $30 \mathrm{~s}$. The PL spectrum from sample F2 has been reported previously ${ }^{13}$ and shows that Er-related luminescence is still observable though it is weaker and has a different shape than the corresponding luminescence from sample O2. This indicates that a different optically active Er center is present.

\section{DISCUSSION}

$\mathrm{Er}^{3+}$ with eleven $4 f$ electrons has a spin-orbit ground state of $J=\frac{15}{2}$ and is separated from the first excited state ${ }^{4} I_{13 / 2}$ by $\sim 6500 \mathrm{~cm}^{-1}$. When the $\mathrm{Er}$ atom is incorporated into the $\mathrm{Si}$
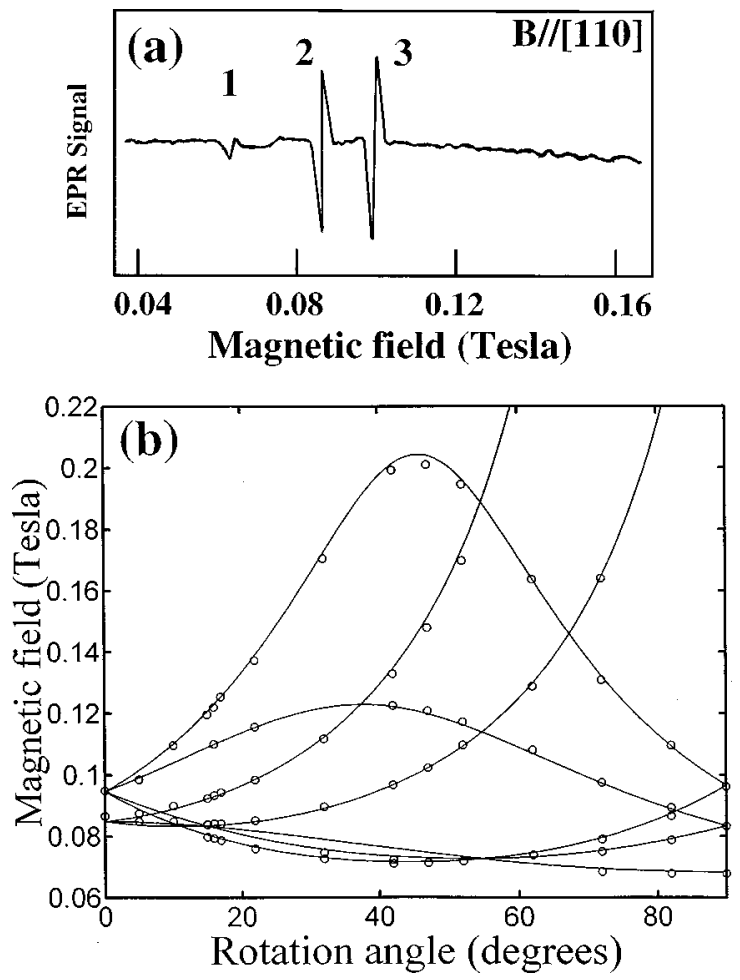

FIG. 10. (a) Low-temperature EPR spectrum from sample F1 $\left(10^{19} \mathrm{Er} / \mathrm{cm}^{3}+10^{20} \mathrm{~F} / \mathrm{cm}^{3}+450{ }^{\circ} \mathrm{C}\right.$ for $30 \mathrm{~min}+620{ }^{\circ} \mathrm{C}$ for $\left.3 \mathrm{~h}\right)$ with the magnetic field parallel to the [110] direction. (b) Angular dependence of the observed resonances (open circles) from sample F1 $\left(10^{19} \mathrm{Er} / \mathrm{cm}^{3}+10^{20} \mathrm{~F} / \mathrm{cm}^{3}+450{ }^{\circ} \mathrm{C}\right.$ for $30 \mathrm{~min}+620^{\circ} \mathrm{C}$ for $\left.3 \mathrm{~h}\right)$ and fit (solid lines) attributed to a single $\mathrm{Er}^{3+}$ center with $C_{1 h}$ symmetry. This center is labeled FEr-1.

host, the 16-fold degenerate free ion ground-state energy level is split into a number of Stark levels. The number and type of sublevels can be obtained from group theory and are given by the irreducible representation of the symmetry groups into which the $J$ representation decomposes. ${ }^{21}$ The decomposition of $J=\frac{15}{2}$, in $T_{d}$ symmetry, can be shown to $\mathrm{be}^{22}$

$$
D^{J=15 / 2}=\Gamma_{6}+\Gamma_{7}+3 \Gamma_{8} .
$$

The $\Gamma_{6}$ and $\Gamma_{7}$ are two-dimensional representations of the double cubic group and the $\Gamma_{8}$ is the four-dimensional representation. Which of these five energy levels, corresponding to the different irreducible representations, lies lowest can be calculated in terms of the crystal-field Hamiltonian having a definite total angular momentum $J$,

$$
H=B_{4}\left(O_{4}^{0}+5 O_{4}^{4}\right)+B_{6}\left(O_{6}^{0}-21 O_{6}^{4}\right),
$$

where $O_{n}^{m}$ are the equivalent crystal-field operators expressed as components of $J .^{23}$ The coefficients $B_{4}$ and $B_{6}$ determine the scale of the crystal-field splitting. In order to solve the Hamiltonian in Eq. (3) Lea, Leask, and Wolf ${ }^{24}$ defined two parameters $x$ and $W$ such that

$$
B_{4} F(4)=W x, \quad \text { and } B_{6} F(6)=W(1-|x|),
$$

where $W$ is an energy scale factor and $F(4)$ and $F(6)$ are numerical factors chosen to keep the fourth- and sixth-order matrix elements in the same numerical range; for $J$ 


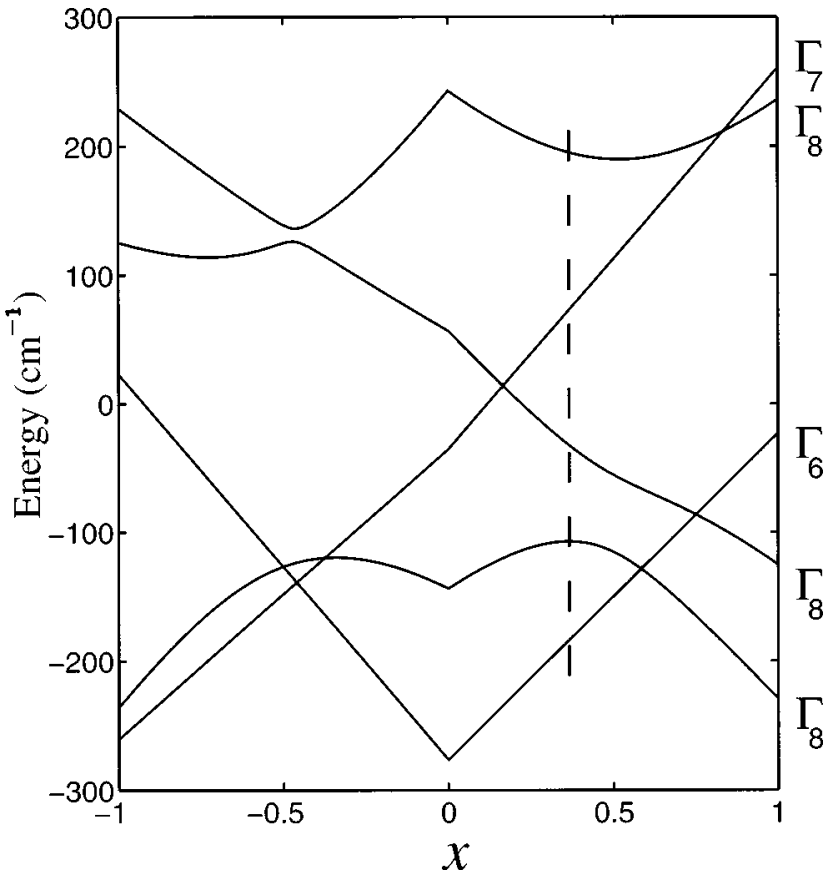

FIG. 11. Crystal-field energy splitting for $J=\frac{15}{2}$ in a cubic crystal field in $T_{d}$ symmetry with $W=0.8635 \mathrm{~cm}^{-1} . x$ is the crystal-field mixing parameter as defined by Eq. (4). The dashed line corresponds to $x=0.35$.

$=15 / 2, F(4)=60$, and $F(6)=13860 .{ }^{24} x$ is the crystal-field mixing term and is expressed in terms of the ratio of $B_{4}$ to $B_{6}$ and runs from -1 to +1 . The eigenvectors of the Hamiltonian are a combination of the fourth- and sixth-order crystal-field potentials. The eigenvalues can be related to the crystal-field energy levels deduced from the observed PL spectrum by the scale parameter $W$. Negative values of $x$ correspond to tetrahedral coordination, whereas positive values of $x$ occur for octahedral coordination. The crystal-field energy level diagram for $\mathrm{Er}^{3+}$ is shown in Fig. 11. With labeling appropriate to $T_{d}$ symmetry, the $\Gamma_{7}$ representation lies lowest for $-1<x<-0.46$, the $\Gamma_{6}$ representation for $-0.46<x<0.58$, and the $\Gamma_{8}$ representation for $x>0.58$. The $\Gamma_{6}$ and $\Gamma_{7}$ representations can be regarded as doublets and application of the Zeeman magnetic field lifts the Kramers degeneracy and EPR can occur between the two time reversed states. Since the Zeeman splitting is small compared to the differences between the crystal-field energy levels, the Zeeman interaction can be regarded as a perturbation to the crystal-field eigenstates. Using the crystal-field eigenstates given elsewhere ${ }^{25}$ the $g$ values associated with transitions within the $\Gamma_{6}$ and $\Gamma_{7}$ states in cubic symmetry are 6.80 and 6.00 , respectively. Paramagnetic resonance can also be observed from a $\Gamma_{8}$ quartet. However, the Hamiltonian associated with a $\Gamma_{8}$ state in cubic symmetry (or the two zero-field split levels derived from a $\Gamma_{8}$ state if the symmetry is less than cubic) contains in addition to those terms found in Eq. (1), third-order spin terms of the form $S_{i}^{3}$, where $i=x, y, z{ }^{25}$ These third-order terms are significant when the spin-orbit interaction is strong and the absence of these terms in Eq. (1) indicates that the centers do not involve $\Gamma_{8}$ symmetry.

If the overall crystal field has less than cubic symmetry, the principal components of the $g$ tensor can be related to the $g$ value predicted for cubic symmetry $g_{c}$ by ${ }^{26-28}$

$$
g_{c}=g_{\mathrm{av}} \equiv \frac{1}{3}\left(g_{1}+g_{2}+g_{3}\right) .
$$

This approach is only valid if the lower symmetry crystal field is small when compared to cubic crystal field. ${ }^{26,27}$ This analysis is also only valid where the $g$ value in cubic symmetry is independent of the strength of the crystal field, which in this case is for the $\Gamma_{6}$ or $\Gamma_{7}$ states. This approach has been used successfully in the interpretation of rare-earth EPR spectra. ${ }^{26-28}$ Small differences $(<0.04)$ between $g_{c}$ and $g_{\text {av }}$ are usually explained in terms of interactions with higher-lying energy levels or the effects of covalency. ${ }^{28}$ If the difference between the value of $g_{c}$ and $g_{\text {av }}$ is large $(>0.1),{ }^{28}$ the assumption that the low symmetry components of the crystal field are small compared to when the cubic crystal field breaks down.

\section{A. Effects of different $O$ concentrations on EPR and PL spectra}

It is apparent from Figs. 1 and 2 that in order to observe sharp EPR lines for an Er concentration of $10^{19} \mathrm{Er} / \mathrm{cm}^{3}$ it is necessary to have in excess of $3 \times 10^{19} \mathrm{O} / \mathrm{cm}^{3}$. At $\mathrm{O}$ concentrations at or below this value, only broad resonances are observed. In the case of sample Er1 (no implanted O present), the single broad isotropic resonance may be due to the formation of Er silicide precipitates. Large clusters of $\mathrm{Er}$ silicide are known to form if the Er concentration exceeds $10^{16} / \mathrm{cm}^{3}$ (the approximately solubility limit of $\mathrm{Er}$ in $\mathrm{Si}$ ). ${ }^{7}$ Although broad resonances are also observed in sample $\mathrm{O} 1$ $\left(3 \times 10^{19} \mathrm{O} / \mathrm{cm}^{3}\right)$, the observed anisotropy of the resonances indicates that the environment around the $\mathrm{Er}$ atom has changed due to the inclusion of O. Whilst no sharp EPR lines are observed from this sample it is possible to fit the four observed PL lines to an $\mathrm{Er}^{3+}$ center having predominantly cubic symmetry using the crystal-field Hamiltonian given in Eq. (3). The best fit to the experimental data was obtained for $x=0.3544$ and $=0.8635 \mathrm{~cm}^{-1}$ with an rms error in the fit of less than $1.7 \mathrm{~cm}^{-1}$. The position of the fifth energy level consistent with cubic symmetry is predicted to be 372.8 $\mathrm{cm}^{-1}$ above the ground state. A transition from the lowest $J=13 / 2$ energy level to this fifth energy level would appear as a PL line centered at $1.6310 \mu \mathrm{m}$. This wavelength lies in a region where the sensitivity of the Ge detector is very low and therefore cannot be detected in the present experiment. A positive sign of $x$ indicates that $\mathrm{Er}$ is incorporated in a $T_{d}$ interstitial site with four nearest neighbors and six nextnearest neighbors lying close by. It is interesting to note that the value of $x$ and $W$ obtained in our analysis are almost identical to those obtained by Przybylinska et al. ${ }^{18}$ in their study of Er-implanted Si and is consistent with the energy level calculation that found the tetrahedral interstitial site to be the most stable for Er to occupy in $\mathrm{Si}^{29}$ These calculations were performed for Er incorporated into pure silicon with no extra impurity present. Furthermore Wahl et al. ${ }^{30}$ have recently experimentally demonstrated, by the emission channeling technique, that $\mathrm{Er}$ is in a tetrahedral interstitial site in float zone $\mathrm{Si}$. A value of $x=0.35$ would imply that the crystal-field ground state has a $\Gamma_{6}$ representation and a single sharp isotropic EPR spectrum with a $g$ value of 6.8 would be predicted. As mentioned previously no sharp EPR line is observed from sample O1 and therefore such cubic $\mathrm{Er}^{3+}$ cen- 
(a)

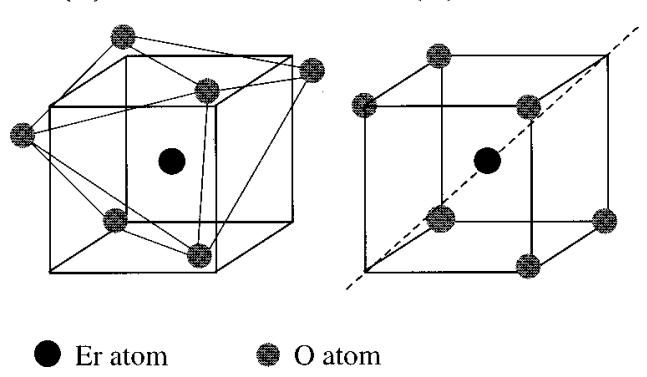

FIG. 12. The arrangement of the $\mathrm{O}$ atoms in the local structure around $\mathrm{Er}$ in $\mathrm{Er}_{2} \mathrm{O}_{3}$ giving rise to (a) monoclinic symmetry and (b) trigonal symmetry. Both structures are similar to the cubic fluorite structure but with $\frac{1}{4}$ of the $\mathrm{O}$ atoms removed. In the case of the monoclinic centers the missing $\mathrm{O}$ atoms are taken from a face diagonal and in the trigonal center the missing atoms are taken from a body diagonal.

ters cannot be the predominantly EPR active centers. However, we can conclude from the anisotropy of the observed EPR spectrum of sample O1 that the EPR active center(s) present has (have) some definite orientation and the fact that it is only seen after coimplantation with $3 \times 10^{19} \mathrm{O} / \mathrm{cm}^{3}$ strongly suggests that the center(s) involves oxygen. The broadness of the lines suggests that the associated $g$ values have a range of values that may arise from a range of different local environments due to the presence of different Er-O-Si and/or Er-O complexes.

At the higher $\mathrm{O}$ concentrations of $10^{20} / \mathrm{cm}^{3}$ in samples $\mathrm{O} 2$ and $\mathrm{O} 4$ the dramatic appearance of a much narrower line EPR spectrum implies that much more well-defined EPR centers have formed. Despite the absence of any hyperfine lines as a positive signature of Er, the high degree of anisotropy is indicative of a paramagnetic center where the orbital angular momentum is not appreciably quenched, such as a rare earth ion. Furthermore the similarity of the principal $g$ values for centers OEr-1, OEr-1', and OEr-3 to those reported ${ }^{26-28}$ for other $\mathrm{Er}^{3+}$ centers strongly suggest that these centers are Er-related centers. In addition the idea that the centers, and also centers OEr-2, OEr-2', and OEr-4, involve $\mathrm{Er}^{3+}$, rather than the non-Kramers ion $\mathrm{Er}^{2+}$, is further confirmed by the fact that they were fitted by the spin Hamiltonian in Eq. (1), which is only appropriate for the Kramers $\mathrm{Er}^{3+}$ ion. ${ }^{17}$ For three reasons we are therefore confident that centers observed here directly involve $\mathrm{Er}^{3+}$. The fact that sharp line EPR spectra are only observed in the presence of a high concentration of $\mathrm{O}$ indicates that well-defined $\mathrm{Er}^{3+}-\mathrm{O}$ complexes are being formed. Since the average $g$ value for center OEr-1 is 6.28 and is sufficiently removed from the $g$ value predicted for cubic symmetry for the $\Gamma_{6}$ or $\Gamma_{7}$ state, the crystal field around the Er atom may have a strong lowsymmetry component. Such a low-symmetry crystal field can be found in the rare-earth oxides. $\mathrm{Er}_{2} \mathrm{O}_{3}$ occurs in two forms each with $\mathrm{Er}^{3+}$ surrounded by six $\mathrm{O}$ atoms: a monoclinic $C_{2}$ center and a trigonal $C_{3 i}$ center as shown in Figs. 12(a) and 12(b). ${ }^{31,32}$ EPR measurements of $\mathrm{Er}^{3+}$ in $\mathrm{Y}_{2} \mathrm{O}_{3}$, which possesses the same local crystal structure as $\mathrm{Er}_{2} \mathrm{O}_{3}$, reveals the presence of $\mathrm{Er}^{3+}$ in both the monoclinic and trigonal sites. ${ }^{33}$ In the case of the monoclinic site the principal $g$ values are $g_{z}=12.314, g_{x}=1.645$, and $g_{y}=4.892$. Not only are the magnitudes of these principal $g$ values similar to those observed for center OEr-1 but also the average $g$ value as defined by Eq. (6) is 6.28, identical to that obtained for center OEr-1. We thus suggest that center OEr-1 (and OEr-1) consists of an $\mathrm{Er}^{3+}$ ion surrounded by six $\mathrm{O}$ atoms in a configuration similar to the monoclinic center found in $\mathrm{Er}_{2} \mathrm{O}_{3}$. The average $g$ value of the dominant trigonal center OEr-2' is 2.39 and since it is well removed from the average $g$ value predicted for a $\Gamma_{6}$ or $\Gamma_{7}$ state, the center OEr-2' could not result from either one of these states. It has further been shown that this center could not arise from a trigonally split $\Gamma_{8}$ state or from an excited state. ${ }^{34}$ Furthermore, the fact that this average $g$ value is sufficiently different from the average $g$ value of the trigonal center observed in $\mathrm{Y}_{2} \mathrm{O}_{3}: \mathrm{Er}^{3+}(6.27)$ suggests that center $\mathrm{OEr}-2^{\prime}$ (and $\mathrm{OEr}-2$ ) is very different from the trigonal center found in $\mathrm{Y}_{2} \mathrm{O}_{3}$ :Er. However, we believe that this center is another well-defined Er-O complex. The remaining centers are also well defined Er-O and/or Er-O-Si complexes though the exact nature of the centers is unclear.

Unlike the EPR spectra, the PL spectrum from sample O2 given in Fig. 9 is similar to the PL spectrum from sample O1. The four PL lines observed in sample $\mathrm{O} 1$ are also present in sample $\mathrm{O} 2$ though reduced in intensity. In addition other PL lines, not associated with the cubic center are also observed. From this we conclude that the optically active cubic $\mathrm{Er}^{3+}$ center is also present in sample $\mathrm{O} 2$ but that the dominant centers responsible for the PL and EPR signals are different.

\section{B. Effects of different anneal treatments on the $\mathbf{O}$ codoped samples}

We now consider the results for samples $\mathrm{O} 2, \mathrm{O} 3, \mathrm{O} 4$, and O5, which have the same impurity concentrations $\left(10^{19} \mathrm{Er} / \mathrm{cm}^{3}\right.$ and $\left.10^{20} \mathrm{O} / \mathrm{cm}^{3}\right)$ but have been subjected to different postimplantation anneal treatments. After implantation the first $2 \mu \mathrm{m}$ of $\mathrm{Si}$ are amorphous and this region is separated by the amorphous-crystalline $(a-c)$ interface from the underlying crystalline substrate. Recrystallization of the amorphous region will occur once the annealing temperature exceeds the crystallization temperature in $\mathrm{Si}\left(\sim 550^{\circ} \mathrm{C}\right) .{ }^{12}$ Sample O3 only received thermal treatment $A$ and the absence of an EPR signal can be explained in terms of little or no SPE regrowth occurring in this sample. EXAFS measurements on this sample have shown that the six nearest neighbors of $\mathrm{Er}$ are all $\mathrm{Si}$ and that the local environment is $\mathrm{ErSi}_{2}$ like. ${ }^{16}$ At a temperature of $620^{\circ} \mathrm{C}$ efficient SPE regrowth is occurring and annealing for $3 \mathrm{~h}$ (treatment $B$ ) is sufficient for the $a-c \mathrm{Si}$ interface to traverse the implanted region. In the absence of $\mathrm{O}$, Polman et al. ${ }^{12}$ have shown that recrystallization produces a redistribution of Er atoms through the migration of the Er ahead of the $a-c$ interface. This will ultimately lead to the formation of clusters of $\mathrm{Er}$ and $\mathrm{Si}$ atoms and to the formation of Er silicide precipitates. We suggest that this explains the broad resonance observed from sample Er1. However, when $\mathrm{O}$ is coimplanted this redistribution of the $\mathrm{Er}$ atoms is inhibited. ${ }^{4} \mathrm{We}$ have already seen that for low $\mathrm{O}$ concentrations $\left(3 \times 10^{10} / \mathrm{cm}^{3}\right)$, Er-Si-O complexes form while at high $\mathrm{O}$ concentrations $\left(10^{20} / \mathrm{cm}^{3}\right)$ Er-Si-O or Er-O complexes are likely to form. Recent EXAFS measurements 
made on these samples have also indicated that a strong interaction between $\mathrm{Er}$ and $\mathrm{O}$ occurs leading to the formation of an O-rich first shell. ${ }^{16}$ The EXAFS measurements made on sample $\mathrm{O} 4$ reveal that after the regrowth process the first coordination shell around $\mathrm{Er}$ is composed of $3 \pm 2 \mathrm{Si}$ and $4.4 \pm 0.6 \mathrm{O}$ atoms. This gives scope for a variety of $\mathrm{Er}-\mathrm{Si}-\mathrm{O}$ and Er-O complexes and may explain our observation of the large number of EPR centers observed in sample O4. The high temperature anneal at $900^{\circ} \mathrm{C}$ for $30 \mathrm{~s}$ (sample O2) helps to reduce the spread of different types of Er-O complexes with the result that the intensities of centers OEr-1 and $\mathrm{OEr}-2$ are larger in sample $\mathrm{O} 2$ than in sample O4. Furthermore centers OEr-3 and OEr-4, which are easily detected in sample $\mathrm{O} 4$, are undetectable from sample $\mathrm{O} 2$. Indeed the EXAFS measurements made on sample $\mathrm{O} 2$ were best fitted by assuming the presence of an average of $5.1 \pm 0.5 \mathrm{O}$ atoms, at an average bond length of $0.227 \mathrm{~nm}$ similar to the bond lengths observed in $\mathrm{Er}_{2} \mathrm{O}_{3}$. However, the absence of any EPR signal from a sample (O5) that has been annealed at $900{ }^{\circ} \mathrm{C}$ for $30 \mathrm{~min}$ indicates that the Er-O complexes observed in EPR are not thermally stable for such an anneal treatment. Comparing the PL spectra from samples O2 (treatment $C$ ) and $\mathrm{O} 4$ (treatment $B$ ) shown in Fig. 9 reveals that the additional anneal of $900^{\circ} \mathrm{C}$ for $30 \mathrm{~s}$ slightly increases the PL intensity though other lines from other optically active centers are also present. This demonstrates the importance of the post implantation annealing conditions in determining the number and type of Er-O complexes. We believe that the principle function of the $\mathrm{O}$ atoms is to increase the effective solid solubility of Er in crystalline Si by forming Er-O complexes and that the optically active and EPR active centers may be different.

\section{Effects of codoping with F}

The principal $g$ values obtained for center FEr-1 are given in Table II. Comparing the two sets of principal $g$ values for center FEr-1 and OEr-1 a number of similarities are apparent. First, both angular dependencies of the spectra can be fitted to a single monoclinic spin $\frac{1}{2}$ center. Furthermore, the average of the $g$ tensor, which can be used as a measure of the strength of the low-symmetry crystal field, is 6.31, similar to that found in OEr-1. Since this value is significantly removed from that calculated for a system with predominantly cubic symmetry, it would indicate that the lowsymmetry crystal field around the Er atom may be strong. Since a strong low-symmetry crystal field was observed to occur in $\mathrm{O}$ implanted $\mathrm{Si}: \mathrm{Er}$ and attributed to the formation of low-symmetry oxide complexes, a similar explanation may be used in the case of F implantation. An examination of the rare-earth fluorides indicates that two possible forms exist: an eight-coordinated complex with a structure similar to $\mathrm{YF}_{3}$ in the form of a distorted tricapped trigonal prism $^{35}$ and an 11-coordinated distorted tricapped trigonal prism having the same structure as the mineral tysonite. ${ }^{36}$ Under the growth conditions for sample $\mathrm{F} 1$, only the $\mathrm{YF}_{3}$ structure is likely to occur; however, to our knowledge, no EPR measurements have been performed on either material. We believe that Er-F complexes are also formed but the exact structure has yet to be determined. Coimplantation with $\mathrm{F}$ should have the added benefit of being able to examine the hyperfine structure from the $100 \%$ abundant $\mathrm{F}^{19}$ isotope $(I=1 / 2)$; however, if $\mathrm{Er}$ is in a structure similar to one of the erbium fluorides then the Er-F distance is approximately $0.33 \mathrm{~nm} \cdot{ }^{37}$ The interaction between $\mathrm{Er}$ and $\mathrm{F}$ may then be treated in a similar manner to the coupling between two point dipoles. ${ }^{36}$ The magnetic field produced by the nuclear magnetic moment of the $\mathrm{F}$ atoms is $^{37}$

$$
B=\frac{\mu_{0}}{4 \pi} \frac{\mu}{r^{3}},
$$

where $\mu=g_{N} \mu_{N} I$ and $g_{N}$ is $5.256 .{ }^{38}$ The magnetic field experienced by the Er atom, taken to be at the Er-F distance of $0.33 \mathrm{~nm}$, is only $37 \mu \mathrm{T}$. Thus even if the Er atom were surrounded by say eight identical $\mathrm{F}$ atoms, the total spacing between the outermost F hyperfine lines would only be 296 $\mu \mathrm{T}$. Since the peak-to-peak width of lines 2 and 3 in Fig. 10 is 1.20 and $1.45 \mathrm{mT}$, respectively, it is not unreasonable that no $\mathrm{F}$ hyperfine interaction is revealed. It is interesting to note that unlike the case of coimplantation with $\mathrm{O}$, coimplantation of $10^{20} \mathrm{~F} / \mathrm{cm}^{3}$ leads only to one well-defined Er-F complex. The PL spectrum from this sample ${ }^{13}$ does not reveal any sharp lines and therefore may be unrelated to the FEr-1 center.

\section{CONCLUSIONS}

Electron paramagnetic resonance spectroscopy has revealed the presence of several Er-impurity complexes, the type and number of which have been shown to depend on the nature and concentration of the implanted impurity and on the annealing conditions. For an $\mathrm{Er}$ concentration of $10^{19} / \mathrm{cm}^{3}$, the observed EPR spectra depend critically on the $\mathrm{O}$ concentration. In the absence of $\mathrm{O}, \mathrm{Er}$ is surrounded by a cage of $\mathrm{Si}$ atoms and for low $\mathrm{O}$ concentrations this cage consists of a mixture of $\mathrm{O}$ and $\mathrm{Si}$ atoms. At high $\mathrm{O}$ concentrations the cage is dominated by $\mathrm{O}$ atoms and the two dominant centers have monoclinic symmetry and trigonal symmetry. No $\mathrm{Er}^{3+}$ in cubic sites was detected by EPR. The EPR active and PL active centers have been shown to be different and we believe that the principal function of the impurity atoms is to prevent precipitation by forming Er-O or Er-F complexes, which leads to an increase in the effective solid solubility of Er in crystalline $\mathrm{Si}$.

\section{ACKNOWLEDGMENTS}

The work in Catania has been supported in part by the EU Project SCOOP and by "Progetto Finalizzato" MADESS II of CNR. 
* Present address: Department of Electronic and Electrical Engineering, University of Surrey, Guildford, GU2 5XH, United Kingdom. Electronic address: D.Carey@ee.surrey.ac.uk

${ }^{1}$ See, for example, Rare Earth Doped Semiconductors, edited by G. S. Pomrenke, P. B. Klein, and D. W. Langer, MRS Symposia Proceedings No. 301 (Materials Research Society, Pittsburgh, 1993).

${ }^{2}$ See, for example, Rare Earth Doped Semiconductors II, edited by S. Coffa, A. Polman, and R. N. Schwartz, MRS Symposia Proceedings No. 422 (Materials Research Society, Pittsburgh, 1996).

${ }^{3}$ J. Michel, J. L. Benton, R. F. Ferrante, D. C. Jacobson, D. J. Eaglesham, E. A. Fitzgerald, Y. H. Xie, J. M. Poate, and L. C. Kimerling, J. Appl. Phys. 70, 2672 (1991).

${ }^{4}$ S. Coffa, F. Priolo, G. Franzò, V. Bellani, A. Carnera, and C. Spinella, Phys. Rev. B 48, 11782 (1993).

${ }^{5}$ G. Franzò, F. Priolo, S. Coffa, A. Polman, and A. Carnera, Appl. Phys. Lett. 64, 2235 (1994); G. Franzò, S. Coffa, F. Priolo, and C. Spinella, J. Appl. Phys. 81, 2784 (1997).

${ }^{6}$ S. Coffa, G. Franzò, F. Priolo, A. Polman, and R. Serna, Phys. Rev. B 49, 16313 (1994).

${ }^{7}$ G. Franzò, F. Priolo, S. Coffa, A. Polman, and A. Carnera, Nucl. Instrum. Methods Phys. Res. B 96, 374 (1995).

${ }^{8}$ F. Y. G. Ren, J. Michel, Q. Sun-Paduano, B. Zheng, H. Kitagawa, D. C. Jacobson, J. M. Poate, and L. C. Kimerling, in Rare Earth Doped Semiconductors, edited by G. S. Pomrenke, P. K. Klein, and D. W. Larger, MRS Symposia Proceedings No. 301 (Materials Research Society, Pittsburgh, 1993), p. 87.

${ }^{9}$ R. Serna, M. Lohmeier, P. M. Zagwijn, E. Vlieg, and A. Polman, Appl. Phys. Lett. 66, 1385 (1995).

${ }^{10}$ J. Stimmer, A. Reittinger, J. F. Nutzel, G. Abstreiter, H. Holzbrecher, and Ch. Buchal, Appl. Phys. Lett. 68, 3290 (1996).

${ }^{11}$ M. Morse, B. Zheng, J. Palm, X. Duan, and L. C. Kimerling, in Rare Earth Doped Semiconductors II, edited by S. Coffa, A. Polman, and R. N. Schwartz, MRS Symposia Proceedings No. 422 (Materials Research Society, Pittsburgh, 1996), p. 41.

${ }^{12}$ A. Polman, J. S. Custer, E. Snoeks, and G. N. van der Hoven, Appl. Phys. Lett. 62, 507 (1993).

${ }^{13}$ F. Priolo, G. Franzò, S. Coffa, A. Polman, S. Libertino, R. Barklie, and D. Carey, J. Appl. Phys. 78, 3874 (1995).

${ }^{14}$ S. Libertino, S. Coffa, G. Franzò, and F. Priolo, J. Appl. Phys. 78, 3867 (1995).

${ }^{15}$ D. L. Adler, D. C. Jacobson, D. J. Eaglesham, M. A. Marcus, J. L. Benton, J. M. Poate, and P. H. Citrin, Appl. Phys. Lett. 61, 2181 (1992).
${ }^{16}$ A. Terrasi, G. Franzò, S. Coffa, F. Priolo, F. D'Acapito, and S. Mobilio, Appl. Phys. Lett. 70, 1712 (1997).

${ }^{17}$ A. Abragam and B. Bleaney, Electron Paramagnetic Resonance of Transition Ions (Oxford University Press, Oxford, 1970), p. 213.

${ }^{18}$ H. Przybylinska, J. Enzenhofer, G. Hendorfer, M. Schoisswohl, L. Palmetshofer, and W. Jantsch, Mater. Sci. Forum 143-147, 715 (1994)

${ }^{19}$ J. D. Carey, J. F. Donegan, R. C. Barklie, F. Priolo, G. Franzò, and S. Coffa, Appl. Phys. Lett. 69, 3854 (1996).

${ }^{20}$ W. Low and R. S. Rubins, Phys. Rev. 131, 1527 (1963).

${ }^{21}$ B. G. Wybourne, Spectroscopic Properties of Rare Earths (Interscience, New York, 1965), p. 28.

${ }^{22}$ A. Abragam and B. Bleaney, Electron Paramagnetic Resonance of Transition Ions (Oxford University Press, Oxford, 1970), p. 858.

${ }^{23}$ M. T. Hutchings, in Solid State Physics 14, edited by F. Seitz and D. Turnball (Academic, New York, 1964), p. 227.

${ }^{24}$ K. R. Lea, M. J. M. Leask, and W. P. Wolf, J. Phys. Chem. Solids 23, 1381 (1962).

${ }^{25}$ A. Kingsley and M. Aven, Phys. Rev. 155, 255 (1967).

${ }^{26}$ J. Dziesiaty, St. Muller, R. Boyn, Th. Buhrow, A. Klimakow, and J. Kreissl, J. Phys.: Condens. Matter 7, 4271 (1995).

${ }^{27}$ U. Ranon and W. Low, Phys. Rev. 132, 1609 (1963).

${ }^{28}$ R. K. Watts and W. C. Holton, Phys. Rev. 173, 417 (1968).

${ }^{29}$ M. Needles, M. Schluter, and M. Lannoo, Phys. Rev. B 47, 15533 (1993).

${ }^{30}$ U. Wahl, A. Vantomme, G. Langouche, J. Marques, and J. G. Correia, Phys. Rev. Lett. 79, 2069 (1997).

${ }^{31}$ G. Brauer, in Progress in the Science and Technology of the Rare Earths, Vol. 1, edited by L. Eyring (Pergamon, New York, 1964), p. 155.

${ }^{32}$ R. M. Moon, W. C. Koehler, H. R. Child, and L. J. Raubenheimer, Phys. Rev. 176, 722 (1968).

${ }^{33}$ G. Schafer and S. Scheller, Phys. Kondens. Mater. 5, 48 (1966).

${ }^{34}$ J. D. Carey, Ph.D. thesis, University of Dublin, Trinity College, 1997.

${ }^{35}$ A. Zalkin and D. H. Templeton, J. Am. Chem. Soc. 75, 2453 (1953).

${ }^{36}$ N. N. Greenwood and A. Earnshaw, Chemistry of the Elements (Butterworth and Heinmann, Oxford, 1984), p. 1074.

${ }^{37}$ A. Abragam and B. Bleaney, Electron Paramagnetic Resonance Ions (Oxford University Press, Oxford, 1970), p. 690.

${ }^{38}$ G. W. C. Kaye and T. H. Laby, Tables of Physical and Chemical Constants and Some Mathematical Functions, 14th ed. (Longman, London, 1973), p. 201. 